\title{
The Relationship Between Dental Caries and YKL-40 Levels in Saliva
}

Gülsüm Duruk ( $\nabla$ durukgulsum@yahoo.com )

İnönü Üniversitesi Diş Hekimliği Fakültesi https://orcid.org/0000-0002-6756-6637

Esra Laloglu

private doctor

Research article

Keywords: Advanced dental caries, DMFT, gingivitis, saliva, YKL-40

Posted Date: August 22nd, 2019

DOl: https://doi.org/10.21203/rs.2.13390/v1

License: (c) (i) This work is licensed under a Creative Commons Attribution 4.0 International License.

Read Full License 


\section{Abstract}

Objective : YKL-40, a new biomarker of localized inflammation, is secreted by macrophages and regulates inflammation and immune responses. The aim of this study was to investigate YKL-40 levels in saliva and compare the level of this mediator in oral cavity. Methods: 85 children (46 girls, 39 boys), aged 6-15 (mean $\pm S D: 9.15 \pm 2.16$ ) were included in this study. The children were divided into three groups: Group-I (control, $n=25, D M F T / d m f t=0)$, Group-II $(n=30$, exist of localized dental caries) and Group-III $(n=30$, exist of localized advanced dental caries). Gingival index (GI), plaque index (PI), DMFT/dmft, DMFS/dmfs, and the number of advanced dental caries according to the ICDAS II and PUFA/pufa index were recorded. Saliva was collected and YKL-40 concentrations were measured. One-way ANOVA with Tukey post hoc , Kruskal-Wallis, multiple regression analysis, and Sperman's correlation tests were used for statistical analysis. Results: The highest level of YKL-40 was obtained in group III , followed by groups II and I, respectively $(p<0.01)$. In Group II, DMFT/dmft scores and the number of caries (DT/dt) were higher than in group III $(p<0.01)$. In group III, there was a statistically significant correlation between $\mathrm{YKL}-40$ levels in saliva and the number of advanced dental caries. In addition, there was no statistically significant difference, with respect to age and gender $(p>0.05)$. Conclusion: Advanced dental caries, rather than DMFT/dmft score, may play an important role in the increasing levels of YKL-40 in saliva.

\section{Background}

In general, pathogenic oral bacteria are classified into two major groups; one is the pathogen for dental caries, and the other is for periodontitis. Gram-positive bacteria (Streptococcus mutans -S. mutans) is a major pathogen of dental caries, while gram-negative bacteria are involved in exaggerated extensive caries and periodontal diseases. ${ }^{1,2}$

Found in shallow caries or in the outer dentinal tubules of deep caries, gram-positive bacteria (Streptococcus and Lactobacillus spp., etc.) are widespread oral microflora. On the other hand, gramnegative bacteria (Fusobacterium, Porphyromonas and Prevotella spp.) are detected in deep caries and in the infected root canals and are related to pulpal and periradicular inflammation. ${ }^{1,3}$

The formation of a dental plaque biofilm is an important biological process associated with the attachment of oral bacteria, in particular $S$. mutans, on the tooth surface. The most common reason of the gingivitis is a mass of supragingival plaque along the teeth's gingival margins where the plague is formed the most. In some cases, observed in a few days, this plague may cause gingivitis to bleed when the plague flora has spirochetes and Actinomyces viscosus. The flora, if not disturbed, step by step, turns to an anaerobic gram-negative flora including black pigmented bacteroides and several types of spirochetes. The low oxidation-reduction potential of the aged-plaque and nutrients taken through the inflammatory exudate can be the reason of the increase in these anaerobic organisms. ${ }^{2}$

YKL-40 is a $40-k D$ a glycoprotein, that is produced by activated macrophages, ${ }^{4}$ neutrophils, ${ }^{5}$ and mast cells in the areas with inflammation. ${ }^{6}$ The plasma levels of YKL-40 are elevated in the patients with 
acute inflammation (e.g. pneumonia, endotoxemia, and hepatitis) or chronic inflammation (e.g. rheumatoid arthritis, inflammatory bowel disease, asthma, chronic obstructive pulmonary disease, type I and II diabetes, and coronary artery disease) and in the patients with liver fibrosis and cancer. ${ }^{7-11}$

In literature, the relationship between the proinflammatory cytokines and the oral pathogenic bacteria was determined. ${ }^{12,13}$ There were also the studies that detected the correlation between these proinflammatory markers and YKL-40 in body fluids. ${ }^{14,15}$

Although there are some studies on YKL-40, only one of them has been performed to investigate the possible role of YKL-40 in oral cavity. ${ }^{16}$. It was related to periodontal diseases and investigated in GCF and serum. We hypothesized that YKL-40 may be an important causative factor, related to the burden of localized inflammation in the oral cavity by oral bacteria and YKL-40 may play a pathophysiological role in this entity. Thus, the goal of this study was to investigate YKL-40 levels in saliva to compare the level of this mediator in a healthy oral cavity and an unhealthy oral cavity, which had dental caries at different stages and poor oral hygiene.

\section{Methods}

\section{Patient selection}

This study was performed in the Faculty of Dentistry, Department of Pedodontics, at Inönü University. According to the previous power analysis clarifying the changes of YKL-40 in saliva, the estimated number of participants was 15 per group, with an alpha level of 0.05 and a power of $0.80 .{ }^{16}$ Samples were analyzed at the Biochemistry Department.

This study was conducted in accordance with the Declaration of Helsinki and after obtaining ethical approval. It was approved by a Clinical Research Ethics Committee in Turkey: Inönü University School of Medicine (ethic number: 2017/67). Written informed consent was obtained from the parents before the examination.

A total of 85 subjects, aged 6-15 (9.15 \pm 2.16 years; 39 male, 46 female) participated in this study. The participants were divided into three groups: Group I (control, $n=25$, mean age=7.72 \pm 1.34 ), Group II ( $n=30$, with dental caries, mean age $=9.40 \pm 2.13$ ) and Group III ( $n=30$, with advanced dental caries, mean age $=10.10 \pm 2.19$ ). The children were excluded from the study if they had any systemic and/or periodontal diseases, and if they took antibiotics or anti-inflammatory drugs in the last 30 days.

\section{Clinical measurements}

All clinical examinations were performed by a single experienced clinician (GD). The examiner was calibrated prior to perform of the study (intra-examiner kappa>0.8) 
The gingival conditions of the patients were evaluated by Silness-Loe plaque index $(\mathrm{PI})^{17}$ and Loe gingival index $(\mathrm{GI})^{18}$. Decayed-missing-filled teeth (DMFT/dmft) and decayed-missing-filled teeth surfaces (DMFS/dmfs) were recorded. The extraction of primary teeth due to physiological root resorption was not recorded as a missing tooth. The teeth were scored using International Caries Detection and Assessment System (ICDAS) $\|^{19}$ and PUFA/pufa index (Exposed pulp, Ulceration, Fistula, Absess) (Table I) ${ }^{20}$. The diagnosis was based on clinical and radiographic features only.

Group I; control. ICDAS II code=0, DMFT/dmft=0

Group II; shallow caries; caries in dentin and cavitation was not exaggerated. ICDAS II code=1-4

Grop III; deep caries; caries lesion was close to the dentin-pulp interface, the dentin thickness was less than $1 \mathrm{~mm}$, with or without pulpal exposure. ICDAS II code=5-6. Group III had at least one tooth with ICDAS II code 5 or 6 . The caries lesions extending into the pulp tissue were classified according to the PUFA/pufa index.

\section{Saliva collection}

All the saliva samples were obtained in the morning and the participants were asked to avoid eating or drinking $1 \mathrm{~h}$ before the collection of samples. All the unstimulated saliva samples were collected by the spitting method and transferred into a 2-ml polypropylene tube. All the saliva samples were homogenized on a Vortex mixer (1 $\mathrm{min})$ and centrifuged $(10,000 \times \mathrm{g}, 10 \mathrm{~min})$ to remove cellular debris. The resultant supernatants of the samples were stored at $-80^{\circ} \mathrm{C}$ for further analysis.

\section{YKL-40 assay}

The level of YKL-40 in saliva was measured by ELISA (R\&D Systems, Minneapolis, MN) and the analysis was performed according to the manufacturer's instructions using human recombinant standards in Biochemistry Laboratory. The results were reported in $\mathrm{pg} / \mathrm{ml}$. The detection limit was $3.5 \mathrm{pg} / \mathrm{mL}$ for YKL40. The samples with YKL-40 levels below the limits of the assay's detectability were scored 0 . The results recorded in $\mathrm{pg} / \mathrm{mL}$ were converted to $\mathrm{ng} / \mathrm{mL}$.

\section{Statistical analysis}

Data analysis was performed using the statistical package SPSS 21 ( SPSS Inc., Chicago Illinois, USA). The results were expressed as means \pm standard deviations. The data were firstly analyzed for the normal distribution with Shapiro-Wilk test. The parameters between the groups were compared with One-way ANOVA, Tukey post hoc and Kruskal-Wallis tests. Multiple regression analysis was used to explain YKL-40 level. Sperman rank correlation test was used to verify the correlations between the parameters.

\section{Results}


DMFT/dmft, DMFS/dmfs, ICDAS II, PUFA, GI, and PI scores were used in this study. For each participant, YKL-40 levels in saliva, the number of decayed, missing, and filled teeth, according to the ICDAS II, and advanced dental caries, according to the ICDAS II and PUFA, were recorded.

There were statistically significant differences among the groups for YKL-40, GI, PI, DMFT/dmft, DMFS/dmfs, the number of shallow caries and the advanced caries $(p<0.01)$ (Table I).

In group III, only 4 patients' oral cavity had dental caries lesions, extending close to the dentin-pulp interface. There were dental caries lesions, which were expected to extend into the coronal pulp in 12 patients. The remaining 14 patients had caries lesions, extending to the total pulp, which were found to have high YKL-40 levels in saliva (Table III). There was a statistically significant correlation between YKL40 and the number of advanced dental caries (Table IV). The positive correlation between YKL-40 and GI were found in all groups (Table $M$ ). In addition, there was no statistically significant difference, with respect to age and gender $(p>0.05)$.

GI score, shallow caries, and advanced caries explain $76 \%$ of the YKL-40 level in saliva. The biggest explanation of the saliva YKL-40 was made by advanced caries $(\beta=0.663)$ (Table $V$ ).

\section{Discussion}

In this study, we found that YKL-40 levels of saliva were significantly higher in an unhealthy oral cavity with caries-deep\&shallow compared with a healthy oral cavity and these levels correlated with dental caries and oral hygiene. Dental caries and periodontal diseases are the most common chronic diseases. Of the more than 300 species of bacteria in the oral cavity, only some of them, known as S. mutans, are caries-causing (cariogenic) organisms. S. mutans is the first bacteria growing in dental plaques. Dental plaque may cause tooth decay, periodontal diseases, or the both at the same time.

There are studies showing that $S$. mutans stimulates the expression of cytokines, TNF-a, IL-1 $\beta$, IFN- $\gamma$. On the other hand, it was reported that IFN- $\gamma$ led to an increase in the production of YKL-40. ${ }^{21-23}$ Based on the results of these studies, it can be conjectured that there is a correlation between YKL-40 and $S$. mutans. In our study, a correlation was found between YKL-40 in saliva and dental caries and it is known that S.mutans is the source of caries.

Keles et al. ${ }^{16}$ found that serum and GCF YKL-40 levels were also significantly higher in the patients with gingivitis and chronic periodontitis than those of control groups. The highest level of YKL-40 was obtained in the group with periodontitis, followed by the group with gingivitis and healthy group, respectively. YKL-40 is considered to be associated with severity of periodontal diseases. In our study, which is similar to Keles et al.'s, YKL-40 levels were gradually increased from healthy group to the group with shallow caries and then to the group with deep caries that was correlated with GI. This correlation can also be related to the situation that in oral cavity with deep caries, chewing cannot be performed well due to both anatomic disruption of teeth and dental pain. So, physiologic cleaning cannot be done in mouth and dental plaques, and this situation increases gingival inflammation in this area. 
In this study, the deep dentinal caries led an increase in the level of YKL-40 in saliva rather than increasing the number of caries teeth. It showed that intense inflammatory properties in oral cavity are more affected by the size of caries than by the number of caries. Gram-positive and negative bacteria can be detected in dental caries. There are different responses of odontoblasts to gram-positive and gram-negative bacteria. The studies on the relationship between tooth caries and cytokines reported that dental caries could lead to inflammation of pulp, resulting in aggregation of inflammatory cells that in turn release inflammatory cytokines. ${ }^{12,13}$

In this study, YKL-40 was considered to be associated with severity of caries and gingivitis. All of shallow and advanced caries teeth and GI in oral cavity descript YKL-40 level in saliva, but the descriptive capacity of advanced caries teeth higher than that of GI and shallow caries teeth.

Data in this field indicate that inflammatory process are responsible for enhancing YKL-40

production ${ }^{14,15}$ Many inflammation markers have been correlated with YKL-40. This study was showed that YKL-40, the indicator of many disease, could also be an indicator of dental caries and gingivitis.

\section{Limitations}

1. No previous studies in this region were available for comparison.

2. Serum levels could not be evaluated because it was difficult to take blood from the children.

\section{Conclusions}

It may be suggested that dental caries, gingivitis, and an infected pulp could increase YKL-40 release in saliva. Additional studies should be conducted to explain the role of YKL-40 in hard and soft tissue pathogenesis in oral cavity, and longitudinal prospective studies with a larger population are needed to confirm the findings of the present study.

\section{Abbreviations}

Gl: Gingival index

Pl: Plaque index

DMFT/dmft: Decayed-missing-filled teeth

DMFS/dmfs: Decayed-missing-filled teeth surfaces

ICDAS: International Caries Detection and Assessment System

PUFA/pufa: Exposed pulp, Ulceration, Fistula, Absess

S. mutans: Streptococcus mutans 
$\mathrm{pg} / \mathrm{mL}$ : Picogram/milliliter

$\mathrm{ng} / \mathrm{mL}$ : Nanogram/milliliter

min: minute

\section{Declarations}

\section{Ethics approval and consent to participate}

Ethical approval was obtained from Clinical Research Ethics Committee in Turkey: Inönü University School of Medicine (ethic number: 2017/67). This study was conducted in accordance with the Declaration of Helsinki. Written informed consent was obtained from the parents before the examination.

\section{Consent for publication}

Authors provide formal written Consent to Publish before publication. The Author grants the Publisher the sole and exclusive license of the full copyright in the Contribution, which license the Publisher hereby accepts.

\section{Availability of data and material}

Not applicable

\section{Competing interests}

The authors declared no potential conflicts of interest with respect to the research, authorship, and/or publication of this article.

\section{Funding}

The authors received no financial support for the research.

\section{Authors' contributions}

GD conceived the idea for the research, wrote the initial framework, performed the statistical analysis, and drafted the manuscript as the principal author. EL participated in the design of the study, performed the biochemical tests in the laboratory, and revised the manuscript.

Both authors read and approved the final manuscript.

\section{Acknowledgements}

The authors wish to thank all participants for their invaluable contribution to this study. 


\section{References}

1. Love RM, Jenkinson HF. Invasion of dentinal tubules by oral bacteria. Crit Rev Oral Biol Med. 2002;13(2):171-183.

2. Loesche WJ. Microbiology of Dental Decay and Periodontal Disease. In: Baron S, ed. Medical Microbiology. 4th ed. Galveston (TX)1996.

3. Sundqvist G. Ecology of the root canal flora. J Endod. Sep 1992;18(9):427-430.

4. Rehli M, Krause SW, Andreesen R. Molecular characterization of the gene for human cartilage gp-39 (CHI3L1), a member of the chitinase protein family and marker for late stages of macrophage differentiation. Genomics. Jul 15 1997;43(2):221-225.

5. Volck B, Price PA, Johansen JS, et al. YKL-40, a mammalian member of the chitinase family, is a matrix protein of specific granules in human neutrophils. Proc Assoc Am Physicians. Jul-Aug 1998;110(4):351-360.

6. Ringsholt M, Hogdall EV, Johansen JS, Price PA, Christensen LH. YKL-40 protein expression in normal adult human tissues-an immunohistochemical study. J Mol Histol. Mar 2007;38(1):33-43.

7. Fontana RJ, Dienstag JL, Bonkovsky HL, et al. Serum fibrosis markers are associated with liver disease progression in non-responder patients with chronic hepatitis C. Gut. Oct 2010;59(10):14011409.

8. Johansen JS, Jensen BV, Roslind A, Nielsen D, Price PA. Serum YKL-40, a new prognostic biomarker in cancer patients? Cancer Epidemiol Biomarkers Prev. Feb 2006;15(2):194-202.

9. Letuve S, Kozhich A, Arouche N, et al. YKL-40 is elevated in patients with chronic obstructive pulmonary disease and activates alveolar macrophages. J Immunol. Oct 1 2008;181(7):5167-5173.

10. Nielsen AR, Erikstrup C, Johansen JS, et al. Plasma YKL-40: a BMI-independent marker of type 2 diabetes. Diabetes. Nov 2008;57(11):3078-3082.

11. Turkyilmaz AK, Devrimsel G, Kirbas A, et al. Relationship between pulse wave velocity and serum YKL-40 level in patients with early rheumatoid arthritis. Rheumatol Int. Nov 2013;33(11):2751-2756.

12. Pezelj-Ribaric S, Anic I, Brekalo I, Miletic I, Hasan M, Simunovic-Soskic M. Detection of tumor necrosis factor alpha in normal and inflamed human dental pulps. Arch Med Res. Sep-Oct 2002;33(5):482484.

13. D'Souza R, Brown LR, Newland JR, Levy BM, Lachman LB. Detection and characterization of interleukin-1 in human dental pulps. Arch Oral Biol. 1989;34(5):307-313.

14. Nielsen AR, Plomgaard P, Krabbe KS, Johansen JS, Pedersen BK. IL-6, but not TNF-alpha, increases plasma YKL-40 in human subjects. Cytokine. Jul 2011;55(1):152-155.

15. Vaananen T, Koskinen A, Paukkeri EL, et al. YKL-40 as a novel factor associated with inflammation and catabolic mechanisms in osteoarthritic joints. Mediators Inflamm. 2014;2014:215140.

16. Keles ZP, Keles GC, Avci B, Cetinkaya BO, Emingil G. Analysis of YKL-40 acute-phase protein and interleukin-6 levels in periodontal disease. J Periodontol. Sep 2014;85(9):1240-1246. 
17. Silness J, Loe H. Periodontal Disease in Pregnancy. II. Correlation between oral hygiene and periodontal condition. Acta odontologica Scandinavica. Feb 1964;22:121-135.

18. Loe H. The Gingival Index, the Plaque Index and the Retention Index Systems. J Periodontol. Nov-Dec 1967;38(6):Suppl:610-616.

19. International Caries Detection and Assessment System (ICDAS) Coordinating Committee. Rationale and Evidence for the International Caries Detection and Assessment System (ICDAS II) [Internet] Scotland: Dental Health Services Research Unit; 2005. Available from: http://www.icdas.org. .

20. Monse B, Heinrich-Weltzien R, Benzian H, Holmgren C, van Palenstein Helderman W. PUFA - An index of clinical consequences of untreated dental caries. Community Dent Oral Epidemiol. Feb 2010;38(1):77-82.

21. Kim JS, Kim KD, Na HS, et al. Tumor necrosis factor-a and interleukin-1 $\beta$ expression pathway induced by Streptococcus mutans in macrophage cell line RAW 264.7. Molecular Oral Microbiology. 2012;27:149-159.

22. Que YA, Moreillon P. Infective endocarditis. Nat Rev Cardiol. Jun 2011;8(6):322-336.

23. Kojima A, Nakano K, Wada K, et al. Infection of specific strains of Streptococcus mutans, oral bacteria, confers a risk of ulcerative colitis. Sci Rep. 2012;2:332.

\section{Tables}

Table I. ICDAS II code 


\section{ICDAS II code}

$0 \quad$ Sound tooth surface, no evidence of caries after prolonged air drying (5 seconds)

1 First visual change in enamel: opacity or discolouration (white or brown) is visible at the entrance to the pit or fissure after prolonged air drying, which is not or hardly seen on a wet surface

2 Distinct visual change in enamel. opacity or discolouration distinctly visible at the entrance to the pit and fissure when wet, the lesion must still be visible when dry

3 Localized enamel breakdown due to caries with no visible dentine or underlying shadow: opacity or discolouration wider than the natural fissure/fossa when wet and after prolonged air drying

$4 \quad$ Underlying dark shadow from dentin, +/- Localised enamel breakdown

5 Distinct cavity with visible dentine: visual evidence of demineralisation and dentine exposed

6 Extensive distinct cavity with visible dentine and more than half of the surface involved

\section{PUFA / pufa index}

$\mathbf{P} / \mathbf{p} \quad$ Pulpal involvement

$\mathrm{U} / \mathbf{u} \quad$ Ulceration

F/f Fistula

A/a Abscess

Table II. The mean \pm SD of YKL-40 levels in saliva and clinic parameters of groups.

\begin{tabular}{|l|l|l|l|}
\hline & Group I & Group II & Group III \\
\hline YKL-40 (ng/mL) & $25.76 \pm 9.29$ & $52.42 \pm 19.18$ & $83.91 \pm 34.54$ \\
\hline DMFT/dmft & $0.00 \pm 0.00$ & $18.03 \pm 3.91$ & $8.80 \pm 2.57$ \\
\hline DMFS/dmfs & $0.00 \pm 0.00$ & $53.40 \pm 10.33$ & $24.23 \pm 8.11$ \\
\hline Fillling teeth (n) & $0.00 \pm 0.00$ & $4.10 \pm 4.37^{\mathrm{a}}$ & $2.83 \pm 1.80^{\mathrm{a}}$ \\
\hline Missing teeth (n) & $0.00 \pm 0.00$ & $4.73 \pm 2.33$ & $1.63 \pm 1.50$ \\
\hline Caries teeth (n) & $0.00 \pm 0.00$ & $9.20 \pm 3.56$ & $4.33 \pm 2.00$ \\
\hline Advanced caries teeth (n) & $0.00 \pm 0.00$ & $0.00 \pm 0.00$ & $2.83 \pm 1.60$ \\
\hline GI & $0.27 \pm 0.23$ & $0.82 \pm 0.34$ & $1.11 \pm 0.41$ \\
\hline PI & $0.78 \pm 0.28$ & $1.07 \pm 0.41^{\mathrm{a}}$ & $1.02 \pm 0.22^{\mathrm{a}}$ \\
\hline
\end{tabular}


$p<0.01$. The same letters in the same row indicate not significant difference $(p>0.05)$

Table III. The distrubition of the advanced caries teeth (n) according to the PUFA/pufa index and the mean values of YKL-40 in group III

\begin{tabular}{|c|c|c|c|}
\hline The number of patients (n) & Advanced caries teeth (n) & PUFA/pufa & YKL-40 \\
\hline & & & Mean \pm Std. Deviation \\
\hline 1 & 1 & A & 132.88 \\
\hline 4 & 1 & $\mathrm{~N}$ & $38.06 \pm 3.11$ \\
\hline 1 & 4 & NNFF & 130.12 \\
\hline 1 & 5 & NNNPP & 106.31 \\
\hline 1 & 4 & NNPP & 113.42 \\
\hline 1 & 5 & NNPPF & 121.21 \\
\hline 2 & 5 & NNPPP & $113.76 \pm 10.54$ \\
\hline 1 & 6 & NNPPPF & 115.93 \\
\hline 1 & 4 & NPFA & 130.12 \\
\hline 1 & 4 & NPPP & 88.81 \\
\hline 3 & 4 & NPPU & $97.01 \pm 14.21$ \\
\hline 3 & 1 & $\mathrm{P}$ & $59.40 \pm 4.18$ \\
\hline 1 & 3 & PFA & 132.88 \\
\hline 2 & 2 & $\mathrm{NP}$ & $46.87 \pm 0.00$ \\
\hline 1 & 2 & NNP & 40.57 \\
\hline 1 & 2 & $\mathrm{PP}$ & 76.21 \\
\hline 1 & 4 & PPPF & 130.12 \\
\hline 3 & 2 & PU & $64.48 \pm 10.93$ \\
\hline 1 & 1 & $\mathrm{U}$ & 62.68 \\
\hline 30 & & & $83.91 \pm 34.54$ \\
\hline
\end{tabular}

Table IV. The correlation between the parameters 
YKL-40

caries

GI

$$
\text { . } \quad \text {. } \quad \cdot
$$

(n)

YKL-40
DMFT/dmft

$\mathrm{DMFS} / \mathrm{dmfs}$

$\begin{array}{lllll}\mathrm{r} ; & \mathrm{r} ; & \mathrm{r} ; & \mathrm{r} ; & \mathrm{r} ; 0.280 \\ 0.502^{* *} & 0.671^{* *} & -0.231 & 0.642^{* *} & \mathrm{p} ; 0.135 \\ \mathrm{p} ; & \mathrm{p} ; & \mathrm{p} ; & \mathrm{p} ; & \\ 0.005 & 0.000 & 0.220 & 0.000 & \end{array}$

0.005

r;

$0.713^{* *}$

$\mathrm{p}$; 0.000

$\mathrm{r}$;

0.326

r;

$0.401^{*}$

r; 0.280

p; 0.134

$\mathrm{p}$; $\quad \mathrm{p}$;

$0.079 \quad 0.028$

$r$;

$-0.146$

$\mathrm{r}$;

$\mathrm{p}$;

0.441

$0.481^{* *}$

r;

$0.578^{* *}$

$\mathrm{p}$;

p; 0.001

Filling

Shallow

caries

Missing

GI

$\begin{array}{ll}\mathrm{r} ; & \mathrm{r} ; \\ -0.496^{* *} & -0.402^{*} \\ \mathrm{p} ; & \mathrm{p} ; 0.028 \\ 0.005 & \\ & \mathrm{r} ; 0.142 \\ & \mathrm{p} ; 0.453\end{array}$

0.007

$\sqrt{2}+x^{2}$




\begin{tabular}{|c|c|c|c|c|c|}
\hline Filling & $\begin{array}{l}\mathrm{r} ; \\
-0.079 \\
\mathrm{p} ; \\
0.679\end{array}$ & $\begin{array}{l}\mathrm{r} ;-0.303 \\
\mathrm{p} ; 0.103\end{array}$ & $\begin{array}{l}\mathrm{r} ;-0.046 \\
\mathrm{p} ; 0.810\end{array}$ & $\begin{array}{l}\mathrm{r} ; \\
-0.075 \\
\mathrm{p} ; \\
0.693\end{array}$ & $\begin{array}{l}\mathrm{r} ; \\
0.131 \\
\mathrm{p} ; \\
0.491\end{array}$ \\
\hline $\begin{array}{l}\text { Shallow } \\
\text { caries }\end{array}$ & & $\begin{array}{l}\mathrm{r} ;-0.271 \\
\mathrm{p} ; 0.148\end{array}$ & $\begin{array}{l}\text { r; } 0.228 \\
\text { p; } 0.227\end{array}$ & $\begin{array}{l}\mathrm{r} ; \\
-0.099 \\
\mathrm{p} ; \\
0.603\end{array}$ & $\begin{array}{l}\mathrm{r} ; \\
-0.273 \\
\mathrm{p} ; \\
0.145\end{array}$ \\
\hline Missing & & & $\begin{array}{l}r ;-0.467^{* *} \\
\text { p; } 0.009\end{array}$ & $\begin{array}{l}\mathrm{r} ; \\
-0.249 \\
\text { p; } \\
0.185\end{array}$ & $\begin{array}{l}\text { r; } \\
0.117 \\
\text { p; } \\
0.540\end{array}$ \\
\hline $\begin{array}{l}\text { Advanced } \\
\text { caries }\end{array}$ & & & & $\begin{array}{l}\mathrm{r} ; \\
0.555^{* *} \\
\mathrm{p} ; \\
0.001\end{array}$ & $\begin{array}{l}\mathrm{r} ; \\
0.280 \\
\mathrm{p} ; \\
0.134\end{array}$ \\
\hline GI & & & & & $\begin{array}{l}\mathrm{r} ; \\
0.395^{*} \\
\mathrm{p} ; \\
0.031\end{array}$ \\
\hline
\end{tabular}

$* \mathrm{p}<0.05 \quad * * \mathrm{p}<0.01$

Table V. Explanation of saliva YKL-40 with multiple regression analysis

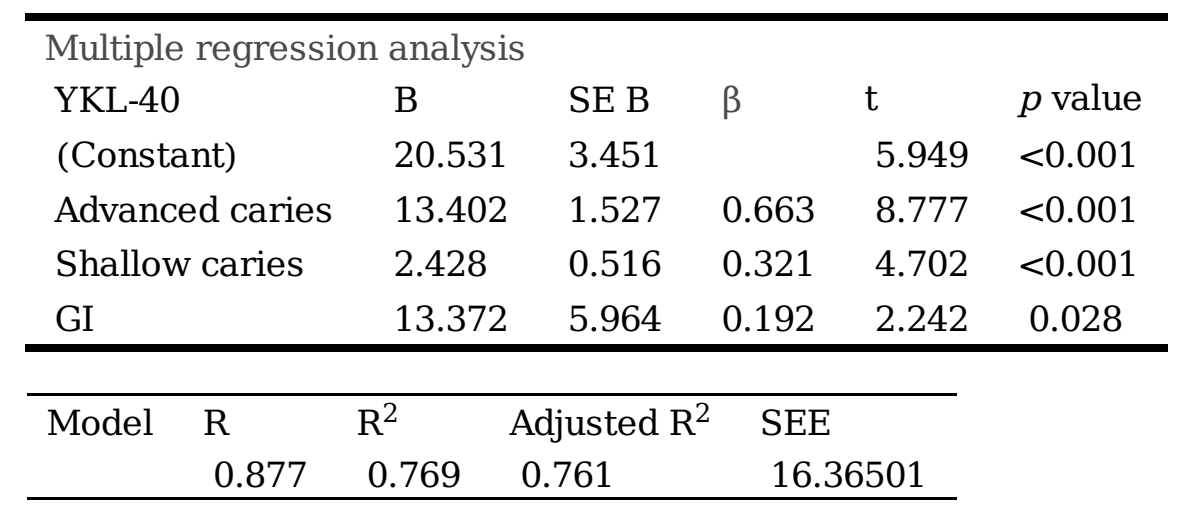

Figures 


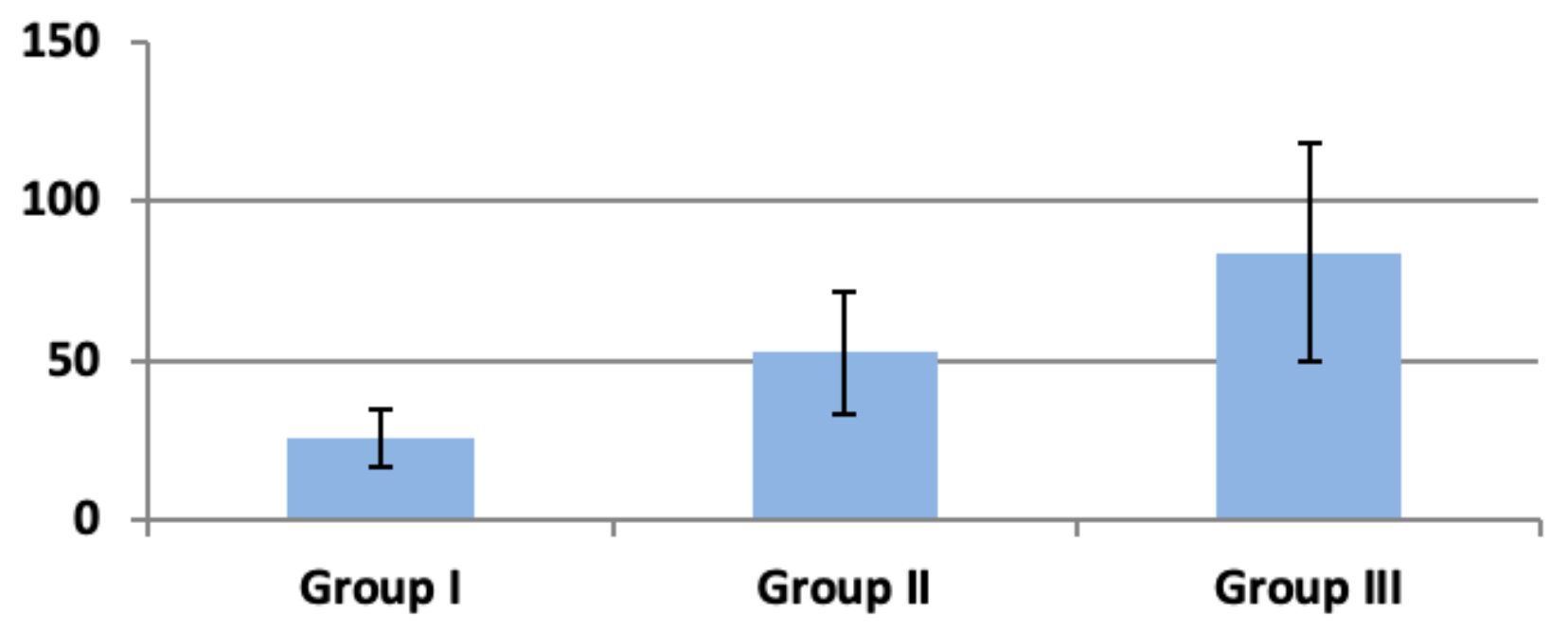

Figure 1

YKL-40 levels $(\mathrm{ng} / \mathrm{ml})$ in groups

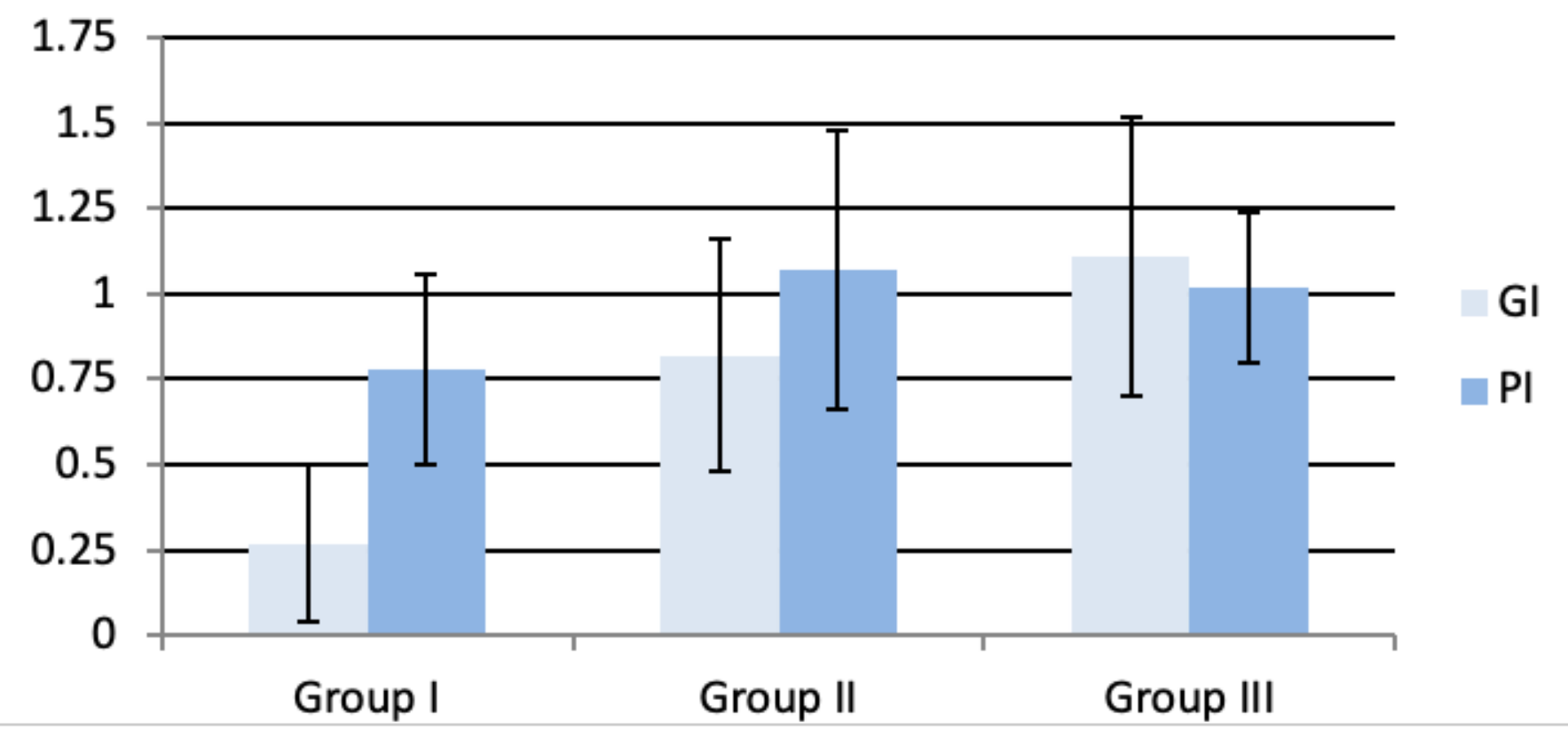

Figure 2

GI and PI levels in groups 